
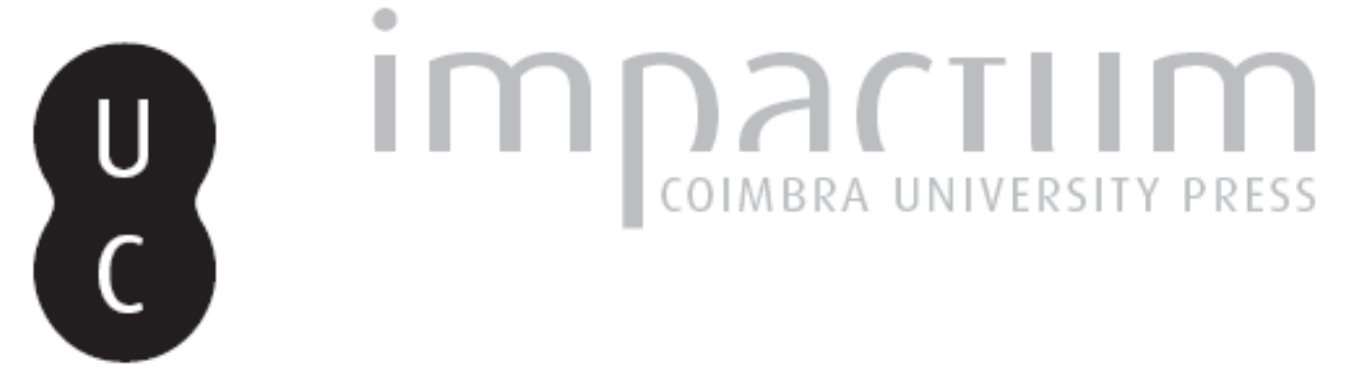

\title{
[Recensão a] Sabah Ferdi, Mosaïques des Eaux en Algérie. Un Language Mythologique des Pierres
}
Autor(es):
Oliveira, Cristina de

Publicado por: Imprensa da Universidade de Coimbra

URL persistente:

URI:http://hdl.handle.net/10316.2/45399

DOI:

DOI:https://dx.doi.org/10.14195/1647-8657_38_14

Accessed : $\quad$ 26-Apr-2023 06:30:36

A navegação consulta e descarregamento dos títulos inseridos nas Bibliotecas Digitais UC Digitalis, UC Pombalina e UC Impactum, pressupõem a aceitação plena e sem reservas dos Termos e Condições de Uso destas Bibliotecas Digitais, disponíveis em https://digitalis.uc.pt/pt-pt/termos.

Conforme exposto nos referidos Termos e Condições de Uso, o descarregamento de títulos de acesso restrito requer uma licença válida de autorização devendo o utilizador aceder ao(s) documento(s) a partir de um endereço de IP da instituição detentora da supramencionada licença.

Ao utilizador é apenas permitido o descarregamento para uso pessoal, pelo que o emprego do(s) título(s) descarregado(s) para outro fim, designadamente comercial, carece de autorização do respetivo autor ou editor da obra.

Na medida em que todas as obras da UC Digitalis se encontram protegidas pelo Código do Direito de Autor e Direitos Conexos e demais legislação aplicável, toda a cópia, parcial ou total, deste documento, nos casos em que é legalmente admitida, deverá conter ou fazer-se acompanhar por este aviso.

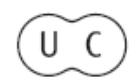


UNIVERSIDADE DE COIMBRA

FACULDADE DE LETRAS

\section{CONIMBRIGA}

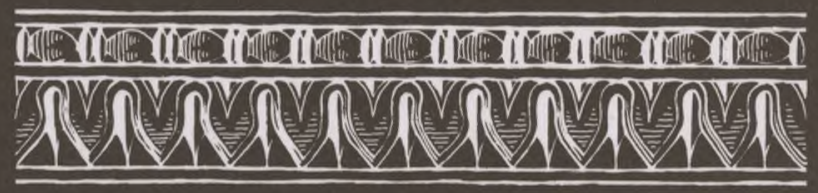

VOLUME XXXVIII - 1999 
Sabah FERDI, Mosaïques des Eaux en Algérie. Un Language Mythologique des Pierres, Paris, 1998.

Sim, o mar é bom: primeiro porque providência às terras a humidade indispensável, penetrando-a com os seus fecundos sucos nas camadas inferiores, graças a canais escondidos. O mar é bom, porque recebe os rios, alimenta as fontes, absorve as terras inúteis, porque favorece as relações comerciais entre povos longínquos, diminue os riscos de guerra, limita os furores bárbaros, serve de refúgio aos perigos, embeleza os prazeres, aproxima os que estão separados, abrevia as distâncias, transporta docilmente os que sofrem, cura por vezes os doentes, transporta os víveres, faz cessar as fomes.

Apesar dos séculos que nos separam destas sábias palavras, proferidas no quarto século do primeiro milénio, elas não perderam o seu sentido no limiar do segundo. Esta mensagem, que a Expo 98 soube veicular ao mundo inteiro, projecta-nos para um elemento determinante na sobrevivência dos povos do planeta: a água. Mundo ainda tão desconhecido para o Homem, que nos dá a vida mas que no-la tira também. Que forças benéficas e maléficas ainda oculta ? Que pode dele esperar o Homem ? Questões primordiais às quais os povos da Antiguidade procuraram dar respostas, criando um imaginário próprio que não padeceu ao longo da História. Desmistificados, em parte, a partir do séc. XV, obra de orgulho nacional, os mundos marinhos e fluviais retomaram um lugar de honra com a realização da Expo 98, trazendo a Lisboa um património que é universal.

Do vasto legado multicultural, subordinado ao tema dos Oceanos, que a última exposição do século nos deixou, cabe-nos aqui realçar uma obra de inestimável riqueza. Apresentada no dia dedicado à Argélia, no pavilhão do país, a obra de Sabah Ferdi é um precioso documento iconográfico para o estudo do mundo aquático e do seu imaginário mitológico na Antiguidade, mormente entre os séc. III-IV. O desatavio do texto e o esplendor das ilustrações constituem, sem qualquer margem para dúvidas, o grande atrativo desta obra. Esta é nos oferecida numa magnífica encadernação de tecido cor de cereja com uma sobrecapa ornamentada com um mosaico de peixes e coberta com uma fina película azul marinho, criando a ilusão óptica de um meio aquático, constituindo um excelente trabalho gráfico.

Estruturada por temas, ao longo de 193 páginas, nela são abordadas as divindades aquáticas maiores e menores representadas em mosaicos, tais como Oceano, Neptuno, as personificações de rios, as Ninfas, as Nereides, Vénus, mas também monstros marinhos, o rapto de Europa, cenas piscatórias ou simplesmente aquáticas, embarcações, cenas de festas, nadadores ou ainda cenas épicas, como é o caso da viagem de Ulisses. Um manancial de obras de arte provenientes de Djemila 
(doze), Timgad (dez), Cherchel (nove), Annaba (oito), Constantine (seis), Lambèse (seis), Oran-Bethioua (cinco), Tipasa (dois), Bejaïa (dois), Guelma (dois), Sétif (dois), Tébessa (dois), Cap Matifou (um), Oued Athmenia (um), Skikda (um) e do Museu Nacional de Antiguidades de Argel (oito).

Cada capítulo é introduzido através de uma fotomontagem alusiva à temática apresentada: ora um mar revolto cuja espuma deixa entrever uma máscara de Oceano, ora um rio correndo na floresta aos pés de um Ninfa. Alguns excertos de obras clássicas, criteriosamente seleccionados, acompanham as fotomontagens. Destacam-se S. Agostinho, Draconius, Eurípedes, Homero, Plínio-o-Jovem, Tertuliano ou Vergilio, para citarmos apenas alguns.

Enquanto obra de divulgação, para um público leigo na matéria, estamos perante um magnífico trabalho gráfico, com a informação estritamente necessária à compreensão do tema, apoiada por índices e glossários pormenorizados (pp. 184-193), suficientes para aguçar a curiosidade e despertar o interesse em ver estas obras primas, quer nos sítios arqueológicos, quer nos museus onde algumas se encontram. Trata-se, pois, de um magnífico cartaz turístico argelino, rematado com um mapa de todos os locais citados.

Do ponto de vista científico, a informação é reduzida, cerceando as necessidades dos estudiosos em mosaico. Aliás, esse não foi concerteza o seu objectivo. O inventário dispõe, é certo, do essencial: a localização do mosaico no edifício, o ano do achado, o paradeiro, as dimensões, uma brevíssima descrição e a datação. Estes elementos podem apenas constituir um ponto de partida a quem se dedica ao estudo deste tema. Por outro lado, a qualidade de certas fotografias pode também ser de alguma serventia no que se refere ao estudo da paleta de cores utilizada pelo mosaicista, pesem embora as limitações de algumas delas. Os problemas de iluminação que se colocam ao registo fotográfico de mosaicos em espaços cobertos é sobejamente conhecido. De qualquer forma, ainda assim, podemos usufruir de cerca de 132 fotografias e sete desenhos de mosaicos, cuja utilidade não pode ser de todo rejeitada pelos especialistas.

Conhecida pela sua riqueza musiva da época romana, a região norte-africana tem sido o alvo predilecto dos especialistas na matéria. $\mathrm{O}$ mundo aquático constituiu certamente uma das temáticas de maior realce, com um carácter excepcional de beleza e perfeição que marcou uma tendência de moda e influenciou o resto do Império. De resto, bastará olhar para as máscaras do deus Oceano, sete, no total de dez apresentado por S. Ferdi. Uma imagem forte, tipicamente africana, de recorte técnico perfeito na maior parte dos casos, tratada com uma policromia judiciosamente aplicada por forma a realizar complexas gradações nas zonas das barbas e cabelos, imprimindo ao olhar uma expressividade própria, características estas que lhe conferem uma presença majestática. Em Portugal, podemos contemplar também uma dessas máscaras de Oceano no Museu de Faro. Acompanhado aqui pelos ventos, a singularidade deste mosaico reside sobretudo na inscrição que o acompanha e cuja leitura interpretada tem levado a caracterizar este pavimento como o de um edifício público, com uma decoração alusiva às actividades marítimas e uma menor carga mitológica. Está datado de finais do séc. II - princípios do séc. III. 
As Nereides, ninfas do Mediterrâneo, montadas em monstros marinhos constituem também um tema predilecto dos ateliers norte-africanos. Contámos vinte e três mosaicos subordinados ao tema, com especial destaque para Tétis e o mortal Peleu, pais do herói Aquiles, Galateia e Polifemo, assim como Anfitrite. No mosaico do frigidarium das termas da villa de $\mathrm{St}^{\text {a }}$ Vitória do Ameixial (Estremoz), figuram também Nereides montadas em Tritões e circundadas por fauna marinha. Aliás, no mesmo mosaico onde figura a cena épica de Ulisses e as Sereias, do canto XII da Odisseia, frequentemente citado e comparado ao exemplar de Cherchel apresentado por S. Ferdi, aqui situado num muro interno de um tanque.

Merecem ainda particular destaque os onze mosaicos de Vénus, com especial veneração pela "toilette" da deusa. As restantes temáticas incidem sobre a vida aquática e o seu meio ambiente: oito ricos mosaicos com uma inesgotável informação sobre a fauna na Antiguidade, um mosaico com uma paisagem terrestre vista do mar - monumentos, pórticos, um templo com uma quadriga no topo, uma casa com colonata e uma ponte de madeira, embarcações de guerra e de comércio. Em Portugal, conhecemos também alguns mosaicos com fauna marinha, alguns deles em contextos termais como é o caso do Campo das Carvalheiras e do Cemitério de Santiago em Braga, de Canelas, em Poiares da Régua, de Milreu (Estoi), mas também os encontramos em Pisões (Beja), em Torre de Ares (Tavira), em Pedras d'El Rei (Tavira) e no Montinho das Laranjeiras (Alcoutim). Certamente influenciados pelos seus congéneres africanos, mas com uma conotação marítima mais esbatida, a não ser o caso paradigmático de Milreu.

$\mathrm{O}$ advento do Cristianismo marcou definitivamente o fim da temática pagã, mas os mosaicos não perderam a sua beleza e a sua força enquanto veículos de mensagens com o simbolismo que lhes é próprio. Neste contexto, os peixes ocuparam um lugar de eleição. E o caso do mosaico da necrópole ocidental de Tipasa, datado do séc. IV, que apresenta a inscrição: IN DEO/PAX ET CONCORDIA SIT/CONVIVIO NOSTRO, acompanhada pelo crismon e por dez peixes diferentes (p. 163).

Embora não influencie decisivamente a opinião global acerca da obra, há contudo alguns aspectos deste inventário que deviam ter merecido maior cuidado, uma vez que estamos perante uma obra promovida pelo Commissàrio Geral da Argélia para as Exposições de Lisboa 98 e Hannover 2000:

- Para a capa e a forra interior da obra, foi escolhido o episódio de Ulisses e as Sirenes, de Cherchel, não o tendo contudo indicado em nenhuma legenda. Por outro lado, não compreendemos por que motivo apenas se apresenta meio barco na capa, tendo sido cortada a outra metade da fotografia.

- Numa obra onde se privilegiou o impacte visual, não gostámos de ver as páginas que separam as temáticas totalmente brancas.

- Também lamentamos o facto de não podermos usufruir da totalidade das ilustrações dos mosaicos citados. Assim, não pudemos observar o mosaico dos esponsais de Neptuno e Anfitrite de Djemila, nem de Neptuno com tridente, exposto no Museu de Oran (p. 39). No seu lugar, oferecem-nos uma fotografia de um ribeiro, muito pouco pertinente. O mesmo aconteceu na p. 43, com o cortejo marinho 
do Museu de Timgad e na p. 47, com a personificação de um rio de uma residência de Annaba. Adiante, na p. 53, não vêm ilustrados outros dois mosaicos também expostos no Museu de Oran. Nap. 101, pela primeira vez, a A. explica a ausência de ilustração do mosaico de Vénus e das Nereides do triclinium da Casa de Vénus em Annaba, por este se encontrar coberto. Na p. 126, também nos privaram do mosaico de Cila, do Museu de Hippone e, na p. 147, foi a vez do pescador de dourada de Djemila.

- É frequente urna certa desorganização na apresentação das legendas.

De facto, são incluídas ampliações de pormenores de mosaicos cuja identificação é omitida ou deslocada para outra página. Verificámo-lo nas pp. 22-23, 50-53, 55-59, 86-87, 152-153, 166-167 el76.

- Por falta de correcta revisão da obra, duas fotografias estão invertidas: a ampliação da Nereide situada mais à esquerda do mosaico do Museu de Lambèse (p. 59) e o mosaico de Ulisses e as Sereias de Cherchel (pp. 118-119).

- Apesar de nos termos já pronunciado quanto à qualidade da maior parte das fotografias, não podemos deixar de lamentar a má qualidade da do mosaico marinho com máscaras de Oceano do Museu de Hippone (Annaba) que invalida qualquer tipo de leitura (pp. 26-27).

Melhor síntese final não poderia ter sido feita pela A.: a água é, simultaneamente, fonte de vida, regeneradora e alimentadora, meio de comunicação mas também lugar de poderes maléficos. Esta relação que o romano manteve com o meio marinho, ao mesmo tempo frutífera e aterradora, foi de tal forma interiorizada que as suas manifestações não se restringem às zonas litorais, mas foram transportadas para regiões interiores, onde já não é o mar que apela, mas sim as fontes e os rios, tão elementares para a vida humana. As províncias do norte de África, mais do que qualquer outra parte do Império, receberam do Mar grande parte da sua riqueza económica e da sua cultura que, através dele, souberam, sabiamente, devolver aos outros. O mare nostrum, centro nevrálgico da economia romana, ligando os dois Impérios, ocidental e oriental, foi perdendo o seu papel ao longo da História, em favor de outros mares, contudo, para a memória do Homem, ele perdurará como um importante pòlo cultural e como a eterna morada dos deuses do Olimpo.

CRISTINA DE OLIVEIRA

LIDIO GASPERINI, Iscrizioni latine rupestri nel Lazio. I - Etruria Meridionale. "Richerche sul Lazio" 1. Roma, 1989, 156 p. + tav. XXXII.

Pubblicato nel 1989, il volume del Gasperini rende conto dello studio condotto dal Dipartimento di Storia dell II Università di Roma su una particolare tipologia di manufatto epigrafico: le iscrizioni rupestri latine, limitatamente all'Alto Lazio.

Conimbriga, 38 (1999), p. 225-246 